\title{
Russian Sentence Corpus: Benchmark measures of eye movements in reading in Russian
}

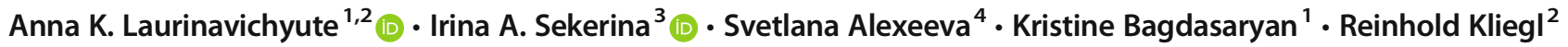

Published online: 15 June 2018

(C) Psychonomic Society, Inc. 2018

\begin{abstract}
This article introduces a new corpus of eye movements in silent reading - the Russian Sentence Corpus (RSC). Russian uses the Cyrillic script, which has not yet been investigated in cross-linguistic eye movement research. As in every language studied so far, we confirmed the expected effects of low-level parameters, such as word length, frequency, and predictability, on the eye movements of skilled Russian readers. These findings allow us to add Slavic languages using Cyrillic script (exemplified by Russian) to the growing number of languages with different orthographies, ranging from the Roman-based European languages to logographic Asian ones, whose basic eye movement benchmarks conform to the universal comparative science of reading (Share, 2008). We additionally report basic descriptive corpus statistics and three exploratory investigations of the effects of Russian morphology on the basic eye movement measures, which illustrate the kinds of questions that researchers can answer using the RSC. The annotated corpus is freely available from its project page at the Open Science Framework: https://osf.io/x5q2r/.
\end{abstract}

Keywords Reading $\cdot$ Eye movements $\cdot$ Russian $\cdot$ Ambiguity $\cdot$ Part of speech $\cdot$ Corpus

\section{Introduction}

Eye movements in reading have been a research topic since Huey (1908), whereas psycholinguistic research started in the 1970s. Since then, measures of eye movements have been the most widely used behavioral data in empirical linguistic research, ranging from testing cognitive models of eye movement control in reading (Rayner, 2009) to core questions of psycholinguistic theory, such as the timing of processing difficulties in complex sentences and interaction between attention and eye movements in language production and comprehension (Rayner, 1998; Rayner, Chace, Slattery, \& Ashby, 2006; Clifton, Staub \& Rayner, 2007). Eye movements have been recorded during the reading of single words, sentences, paragraphs, and whole texts

Anna K. Laurinavichyute

alaurinavichute@hse.ru

1 National Research University Higher School of Economics, Staraya Basmannaya, house 24/1 c.1, Moscow, Russian Federation 105066

2 University of Potsdam, Karl-Liebknecht-Straße 24-25, Potsdam 14476, Germany

3 College of Staten Island and the Graduate Center of the City University of New York, Staten Island, NY, USA

4 St.-Petersburg State University, St. Petersburg, Russia in languages with different orthographies. Their analysis allows us to establish the fundamental characteristics of eye movements within and across languages, which are referred to as eye movement benchmarks. The reading materials, together with the eye movement benchmarks collected from individuals reading these materials, constitute corpora of eye movements that have started to appear in the past 20 years.

Eye movement corpora are an indispensable tool for basic research in cognitive psychology and psycholinguistics. First, they serve as a source of data for establishing the basic benchmarks of eye movements while reading in languages with typologically diverse orthographies and grammars, and they constitute an important testing ground for models of eye movements in reading - for example, the E-Z Reader model (Reichle, Pollatsek, Fisher, \& Rayner, 1998) and the SWIFT model (Engbert, Longtin, \& Kliegl, 2002). Second, eye movements reflect typical linguistic behavior - that is, the silent reading process - and serve as a natural material to evaluate theories of language processing in psycholinguistics. For example, Gibson's (2000) dependency locality theory was tested on eye movement data in English (Demberg \& Keller, 2008) and Hindi (Husain, Vasishth, \& Srinivasan, 2015); the entropy rate principle (Genzel \& Charniak, 2002) was tested on an English corpus (Keller, 2004); and the surprisal account (Hale, 2001) was confirmed for the Potsdam Sentence Corpus (Boston, Hale, Kliegl, Patil, \& Vasishth, 2008). Finally, eye-movement-while- 
reading corpora provide the necessary control data to study the acquisition of literacy in unskilled (Ashby, Rayner, \& Clifton, 2005) and bilingual (Cop, Dirix, Drieghe, \& Duyck, 2017) adults, as well as the developmental and acquired reading difficulties in children with and without learning disabilities (Tiffin-Richards \& Schroeder, 2015) and in adults with cognitive impairments, such as aphasia (Ablinger, Huber, \& Radach, 2014) and Alzheimer's disease (Crawford, Devereaux, Higham, \& Kelly, 2015).

The basic benchmarks of eye movement control in reading include measures related to fixation probabilities and fixation durations. These benchmarks were first established for reading in English, a language with the Roman-based alphabetic script and a deep orthography, by Huey in 1908 (see also Tinker, 1958). Follow-up studies revealed that these benchmarks vary depending on the lexical characteristics of words - that is, their frequency, length, and predictability from context. The benchmarks also determine the probability of a word being fixated or skipped, the expected number of fixations on it, and the probability of regression to it later. In recent years, other factors - for example, word familiarity, age of acquisition, polysemy, and plausibility — have been added to the inventory of characteristics that influence eye movements in reading.

In the 1990s, as psycholinguistics in general started to rapidly expand from English into other languages, it became clear that the focus on the English language in reading research was slowing down the development and empirical testing of "a universal science of reading" (Share, 2008, p. 584). Eye movements in reading in other Roman script-based languages, namely, French, German, Dutch, and Finnish, that have more transparent orthography, but more complex morphology, often differ from English. Thus, it was found that eye movement benchmarks were affected by parafoveal word familiarity in French (Kennedy \& Pynthe, 2005), word position in the sentence in Dutch and Spanish (Fernández, Shalom, Kliegl, \& Sigman, 2014; Kuperman, Bertram, \& Baayen, 2010a), and complex derivational and inflectional morphology in Finnish (Hyönä, Laine, \& Niemi, 1995).

Recently, there has been a virtual explosion of comparative cross-linguistic research on reading in typologically diverse languages with non-Roman orthographies, such as Chinese (Bai, Yan, Liversedge, Zang, \& Rayner, 2008; Yan, Richter, Shu, \& Kliegl, 2009; Tsai, Kliegl, \& Yan, 2012; G. Yan, Tian, Bai, \& Rayner, 2006), Japanese (Sainio, Hyönä, Bingushi, \& Bertram, 2007), Korean (Kim, Radach, \& Vorstius, 2012), Hebrew (Pollatsek, Bolozky, Well, \& Rayner, 1981), Thai (Winskel, Radach, \& Luksaneeyanawin, 2009), Hindi (Husain et al., 2015), Arabic (Paterson, Almabruk, McGowan, White, \& Jordan, 2015), Urdu (Paterson et al., 2014), and Uighur (M. Yan et al., 2014). Their visual, orthographic, lexical, and sentence-level characteristics required modification of existing models of reading and psycholinguistic theories. For example, it was found that in nonspaced logographic scripts, such as traditional Chinese, the average saccade length is much shorter (two to three character spaces) than in the spaced scripts (eight). However, in unspaced scripts, readers are able to direct their eyes toward the preferred viewing location (close to the middle of the word), just as in spaced scripts, in which the between-word spaces can be used to estimate word length (M. Yan, Kliegl, Richer, Nuthmann, \& Shu, 2010; for similar results in Thai, see Winskel et al., 2009).

Nonetheless, even if we take all the studied European Roman script-based, Arabic, and Asian logographic languages together, their number remains very small as compared to the world's 80 writing systems. What is inconspicuously absent in the abovementioned research is languages that use the Cyrillic orthography, namely the five major Slavic languages (Russian, Ukrainian, Belarusian, Serbian, and Bulgarian) and more than 100 languages from other language families whose newly established writing systems were based on Cyrillic alphabet - that is, the indigenous languages of the former Soviet Union (Lewis, 1972). The languages that use Cyrillic script are typologically very diverse: They belong to such language families as Slavic, Turkic (Tatar, Kyrgyz), Caucasian (Abkhaz, Adyghe), Mongolic (Mongolian), and so forth. Their omission in cross-linguistic research on eye movements in reading is a sizable lacuna in the comparative science of reading that should be universal (Share, 2008).

In this article, we will focus on Russian as a representative Slavic language that uses the Cyrillic alphabet, with more than 160 million speakers in the Russian Federation alone. The transparency of its writing system puts it in the middle of the continuum, between shallow (Finnish) and deep (English) orthographies. Several characteristics of Russian, especially its phonology (e.g., nonsystematic stress patterns, conditional pronunciation in the form of vowel reduction and consonant assimilation, complex syllable structure, and long polymorphemic words) as well as its rich inflectional and derivational morphology, are of considerable interest for comparative reading research. We introduce the Russian Sentence Corpus (RSC), which is the first systematic corpus of basic benchmarks of eye movements in reading in Russian by skilled young adults that extends the existing eye movement corpora of European Roman-based and Asian logographic languages to include Cyrillic.

\section{Toward a common protocol for cross-linguistic eye movement corpora}

Despite the fact that there are several cross-linguistic corpora of eye movements in reading, they are difficult to compare because of discrepancies in stimuli materials, data-collecting methods, and statistical analysis techniques. This is one of the 
reasons of why cross-linguistic progress has been so slow. The solution is to develop a common protocol that provides guidelines for creating a set of reading materials that are tightly controlled along several design manipulations that influence eye movements in other languages.

\section{Eye movement corpus for English (Schilling et al. 1998)}

Schilling, Rayner, and Chumbley (1998) constructed 48 English sentences containing either one of 24 low- or one of 24 high-frequency target words closely matched in length and preceded by a neutral sentence context. The goal was to compare frequency effects in lexical-decision reaction times, isolated word naming, and various measures of fixation durations during sentence reading. Reichle, Pollatsek, Fisher, and Rayner (1998) added cloze predictabilities (a measure of how successfully a word can be guessed on the basis of the previous context; see the next section for details) for all Schilling et al.'s words, and then used the fixation durations and probabilities to fit the parameters of the E-Z Reader model. The Schilling data were also used to test the first version of the SWIFT computational model of eye movement control (Engbert \& Kliegl, 2001; Engbert et al., 2002).

The successful fit of several computational models to the same data has motivated an extension of this approach to other languages, to systematically test both the universal and language-specific characteristics that may affect eye movements in reading and language comprehension. The idea was to design similar materials across languages regardless of the type of orthography and create a protocol that could be flexible enough to choose language-specific grammatical features and structures.

\section{Eye movement corpus for German: Potsdam Sentence Corpus (Kliegl et al., 2004)}

Kliegl, Grabner, Rolfs, and Engbert (2004) expanded the Schilling et al. (1998) protocol, which resulted in the creation of the Potsdam Sentence Corpus (PSC). The initial step in the protocol was the selection of target words by orthogonally manipulating their three lexical characteristics in a $2 \times 3 \times 2$ design: part of speech, length in characters, and frequency. Only two parts of speech were included, nouns and verbs. Length in characters had three levels: short (3-4 characters), medium (5-7), and long (8-12). Frequency was either high, $>50$ items per million (ipm) or low, $1-4 \mathrm{ipm}$. Twelve target words were selected for each cell of this between-items design resulting in a total number of 144 . Next, a novel sentence was created around each target word in such a way as to provide natural context for it, with the restriction that the target word was never in the sentence-initial or sentence-final position (e.g., Die meisten Hamster bleiben bei Tag in ihrem
Häuschen "Most hamsters stay in their houses during the day"; the target word is in bold). The 144 sentences ranged in length from five to eleven words, with the total number of 1,138 words in the PSC. Grammatical structures of the sentences were simple and represented a variety of syntactic constructions characteristic of German, but they were not parametrically manipulated. The protocol allows for testing hypotheses about eye movement control during reading (a) for all words in the sentences, and simultaneously (b) for target words with tightly controlled characteristics (namely, length, and frequency) that are embedded in the sentences.

The second step in creating the PSC was to collect predictability norms for all its words, in 144 sentences using the cloze task. The predictability norming study preceded data collection for the PSC and was conducted with a separate group of 264 participants, resulting in 83 predictions for each word. Participants started with a blank screen and were asked to type any word. The script then would replace the word typed by the participant by the first actual word from one of the 144 sentences (e.g., Die . . ), and the participant had to guess the second word. At the beginning of the sentence, the participants' chance of guessing the actual word was close to zero, but it improved as they approached the end of the sentence.

The third step was to collect eye movement data and extract the benchmarks from them using monolingual skilled German readers reading the 144 sentences. The statistical analysis of eye movements was conducted first for the 144 target words and then for all the 994 words comprising the corpus (the first word of each sentence was excluded from the analysis). The dependent measures became the basic benchmarks of eye movements in German and were of three types - fixation durations, probabilities of skipping or fixating words, and probabilities of regression saccades (see Data Analyses section). The basic benchmarks of eye movements in reading in German are presented in comparison to those in Russian in "Replication results: Similarities between the RSC and PSC" section (see Table 2 there). In recent years, two additional extensions of the PSC have been added: PSC2 includes data of 85,000 predictions for 1,230 words for the original 144 sentences (Laubrock \& Kliegl, 2015) and PSC3 crossed frequency with predictability within otherwise identical sentential frames (Dambacher et al., 2012; Dambacher, Rolfs, Göllner, Kliegl, \& Jacobs, 2009). The benchmarks of eye movements in reading in German from the PSC have been successfully used to fit and test predictions of later versions of the SWIFT model (Engbert, Nuthmann, Richter, \& Kliegl, 2005; Risse, Hohenstein, Kliegl, \& Engbert, 2014; Schad \& Engbert, 2012).

\section{Other eye movement corpora based on the PSC protocol}

The main parameters of words that influence eye movements - frequency, length, and predictability — are universal 
in that they affect eye movements in the same direction in all languages, regardless of orthography, but the differences between scripts (e.g., orthographic transparency) should yield predictable differences in the sizes of effects. This prediction has been tested in several studies that followed the PSC protocol in a variety of languages. These include French (Kennedy \& Pynthe, 2005), Dutch (the GECO Corpus: Cop, Dirix, Drieghe, \& Duyck, 2017; Kuperman, Bertram, \& Baayen, 2010), Argentinian Spanish (Bahia Blanca; Fernández et al., 2014), Chinese (Bai et al., 2008; Li, Bicknell, Liu, Wei, \& Rayner, 2014; G. Yan et al., 2006; M. Yan et al., 2010), Japanese (Sainio et al., 2007), Thai (Winskel et al., 2009), Hindi (Husain et al., 2015), and Uighur (M. Yan et al., 2014). There is also one study with the same sentences read by Chinese, English, and Finnish participants, each in their respective language (Liversedge et al., 2016).

Regardless of the language, the basic benchmarks that are reported in the literature seem to hold in every language studied: average fixation duration ranges from 220 to $250 \mathrm{~ms}$ and reading times increase with increasing word length and decrease with increasing word frequency. Saccade length and saccade landing position depend more strongly on the writing system. The average saccade length is the longest in alphabetic languages that use Latin script (eight characters), shorter in Hebrew (five), and shortest in Chinese (two or three). The single fixation position is more likely to be at the beginning or middle of the word for Chinese and Japanese, and at the middle for alphabetic languages. In Uighur, an agglutinative language that relies on heavy use of suffixes, landing position is also influenced by the number of suffixes (M. Yan et al., 2014), suggesting that morphological structure of parafoveal words influences saccade programs (also found in Finnish; Hyönä, Yan, \& Vainio, 2017).

For Russian, several studies using eye tracking while reading have already been conducted, but they explored specific theoretical issues in low-level eye movements or sentence processing (Alexeeva \& Slioussar, 2017; Anisimov, Fedorova, \& Latanov, 2014; Bezrukikh \& Ivanov, 2012; Chernova, 2015; Jouravlev \& Jared, 2018). They aimed to answer questions unrelated to particular properties of the Cyrillic alphabet or reading strategies in Russian. In "The present study: Russian Sentence Corpus (RSC)" section we describe our study, whose goal was to identify basic benchmarks in reading in Russian and create the Russian Sentence Corpus following the PSC protocol. To do so, we investigated the effects of length, frequency, and predictability on eye movements and tested a few hypotheses about factors that may be specific for reading in Russian.

Following the PSC and other eye movement corpora based on it, the RSC materials represent isolated sentences. The majority of previously published corpora have used isolated sentences, and only a few have employed coherent texts (e.g., newspaper articles in Kennedy \& Pynthe, 2005; short narratives in Husain et al., 2015; novel reading in Cop et al., 2017). The obvious advantage of using full texts is their higher ecological validity, because such a setup closely resembles natural reading. Coherent texts may be especially interesting to use when studying local predictability and contextual effects. However, one particular genre may be not characteristic of the texts and genres found in the language. In contrast, isolated sentences selected from different texts and genres are more representative of the variability in the language. From a methodological point of view, isolated sentences are also easy to fit on one line on the screen, and therefore avoid line wrap and line switch effects. Presenting material on one line mitigates the problem of runaway fixations that are registered in the vertical space between two lines of text. Thus, full-text corpora that closely resemble natural reading are most useful as a second step in reading research, after basic benchmarks have been identified in an isolated-sentence-based corpus.

\section{The present study: Russian Sentence Corpus (RSC)}

The design of the RSC followed the PSC protocol (Eye movement corpus for German: Potsdam Sentence Corpus (Kliegl et al., 2004) section), with data from 96 monolingual skilled readers of Russian.

\section{Method}

\section{Participants}

We included three groups of participants in the present study, all monolingual Russian-speaking adults. Group $1(n=215)$ provided acceptability judgments for the corpus sentences, Group $2(n=750)$ participated in the predictability norming study, and Group $3(n=96)$ read the corpus sentences. Their eye movements were used to calculate the basic benchmarks for reading in Russian and together with the materials constitute the Russian Sentence Corpus (RSC).

Group 3 that provided data for the main part of the studythat is, reading the sentences from the RSC, consisted of 96 participants (66 women and $30 \mathrm{men}, M_{\text {Age }}=24$, range 18-80). They volunteered for the study and did not receive any compensation for taking part in it. The study was carried out in accordance with the ethical principles of psychologists and code of conduct of the American Psychological Association and was approved by the local Institutional Review Board. All participants gave written informed consent in Russian in accordance with the Declaration of Helsinki. The study took between 25 and $40 \mathrm{~min}$.

\section{Design and materials}

The materials were designed following the PSC protocol (Kliegl, Grabner, Rolfs, \& Engbert, 2004; Kliegl, 
Nuthmann, \& Engbert, 2006), described in "Eye movement corpus for German: Potsdam Sentence Corpus (Kliegl et al., 2004)" section above, with an important modification: In contrast to the PSC, for which the sentences were created by the experimenters around the target words, Russian sentences were randomly selected from the Russian National Corpus (https://Ruscorpora.ru). Using existing sentences increases the ecological validity of a study and potentially allows for more natural contextual embedding of the words into sentences, which might influence the strategies of readers.

First, we randomly selected 144 target words from the StimulStat database (https://stimul.cognitivestudies.ru; Alexeeva, Slioussar, \& Chernova, 2017) using the predefined criteria for a modified $3 \times 3 \times 2$ design in which a word's part of speech, length, and frequency were manipulated. We increased the number of levels for the partof-speech variable from two to three by adding adjectives (e.g., узкой 'narrow-FEM. INSTR. SG') in addition to nouns (e.g., страницьь 'page-FEM. GEN. SG') and verbs (e.g., заварил 'brewed-MASC. PAST. SG'). Each length-frequency design cell contained 12 nouns, six verbs, and six adjectives, except for the short words in which we had to increase the number of nouns to 16 and decrease the number of verbs and adjectives because three or four letter verbs and adjectives (e.g., всей 'entire-FEM. GEN. SG', жить 'to live-INF') are rare in Russian. This affected four of the design cells. The length variable had three levels: short (3-4 characters), medium (5-7), and long (8-10). Frequency was either high (>50 ipm) or low $(<10 \mathrm{ipm})$. For selection of the target words, we used lemma length and lemma frequency information taken from Lyashevskaya and Sharov (2009).

Using the resulting list of 144 target words, we extracted sentences from the Russian National Corpus that included target words in such a way that their position ranged from the third from the beginning to the third from the end of the sentence. We aimed at representing diverse types of syntactic structures typical for Russian including declarative, exclamatory, and interrogative sentences, and sentences with noncanonical word orders, but did not manipulate the grammatical structure parametrically. We replaced complex lexical items with simpler ones and shortened the sentences when they exceeded the preset maximum length of 13 words (for details, see Table 1). Example 1 illustrates how one such long and lexically complex original sentence (1a) from the Russian National Corpus was adapted for the RSC (1b) (the target word лёд 'ice-MASC. NOM. SG' is in bold).

(1) а.В болотах млел ещё жёлтый кислый лёд, но на берегах уже появилась из-под снега прошлогодняя трава и груды торфа.

"The yellow sour ice was still melting in the marshes, but the grass from last year and piles of peat already appeared on the river banks."
b.На болотах оставался ещё лёд, но на берегах реки появилась трава.

"The ice remained on the marshes, but the grass appeared on the river banks."

A representative set of 13 sentences is provided in Appendix A.

Second, the 144 selected sentences were subjected to acceptability norming. We used the Web-based service Virtualexs (https://virtualexs.ru/) designed to conduct online surveys in Russia. Participants $(n=215)$ read each sentence online and were asked to judge its acceptability on a Likert scale ranging from 1 totally unacceptable to 5 perfectly acceptable. The four sentences with mean scores below 3 were modified by our research team.

Third, the 144 modified sentences were used in a predictability norming study (see Eye movement corpus for German: Potsdam Sentence Corpus (Kliegl et al., 2004) section), with one technical modification: We collected the norms online and did not pose any restrictions on the number of sentences each participant guessed. We included data from every participant that made more than 20 guesses out of 1,362 words in the corpus.

The resulting set of 144 sentences was then morphologically annotated. First, an automated annotation was performed using the Mystem algorithm (https://tech.yandex. $\mathrm{ru} / \mathrm{mystem} /$ ): The lemma was identified, tagged for part-ofspeech information and for morphological features (animacy, number, gender, and case for nouns; transitivity, tense, mood, number, gender, and aspect for verbs; etc.). Possible ambiguity between parts of speech and morphological features was noted. Two trained linguists independently reviewed the results of the automated annotation and, if necessary, disambiguated, or corrected them.

The main, and final, step was to collect eye movements from 96 monolingual Russian-speaking participants as they read the entire RSC, which were then used to calculate the benchmarks of eye movements during reading in Russian, described in "Replication results: Similarities between the RSC and PSC" and "Novel results: Exploitation of the RSC" sections, respectively.

\section{Procedure}

Sentences were presented in the middle of a 24-in. ASUS VG248QE monitor (resolution: $1,920 \times 1,080$ pix, response time: $1 \mathrm{~ms}$, frame rate: $144 \mathrm{~Hz}$, font face: $22-$ point Courier New) controlled by a ThinkStation computer. The presentation of the materials and recording of the eye movements were implemented by Experiment Builder (SR Research Ltd.). Participants were tested individually 
Table 1 Descriptive statistics of the RSC and PSC

Russian Sentence

Corpus (This Study)

\# of sentences

Sentence length

\# of words

Word length

Guesses per word

Word length (characters)

(in the form Length -

No. of words)

\section{4}

1,362 words

Range: 1-16

20-151

All words:

$1-102$

$2-88$
Word frequencies

All words:

Target words:

Predictability summary (\%)

all words:

target words:

Predictability distribution

All words:

Target words:
Range: $5-13$ words, $M=9$

1,074 (without first and last words)

$M=5.7, M d n=6$ (all words)

$M=6.3, M d n=6$ (target words)

$3-99$

$4-141$

$5-163$

$6-151$

$7-154$

$8-101$

$9-77$

$10-71$

$11-40$

$12-17$

$13-9$

$13+-5$

(Class - No. of words)

Class 1 (1 - 10 ipm) -

Class 2 (11 - $100 \mathrm{ipm})-$

Class $3(101-1,000)-$

Class $4(1,001-10,000)-$

Class $5(10,001-\max )-$

Class 1 (1 - 10 ipm) -

Class 2 (11 - 100 ipm) -

Class $3(101-1,000)-$

Class $4(1,001-10,000)-$

Class $5(10,001-\max )-$

$M=16 \%, M d n=1 \%$

$M=10 \%, M d n=0 \%$

(Class - No. of words)

Class $1(-2.553$ to -1.5$)-\quad 663$

Class $2(-1.5$ to -1.0$)-\quad 139$

Class $3(-1.0$ to -0.5$)-\quad 115$

Class 4 ( -0.5 to 0$)-\quad 120$

Class 5 (0 to 2.553) - $\quad 181$

Class $1(-2.553$ to -1.5$)-\quad 102$

Class $2(-1.5$ to -1.0$)-\quad 12$

Class $3(-1.0$ to -0.5$)-\quad 11$

Class 4 ( -0.5 to 0$)-$

Class 5 (0 to 2.553$)-$
Potsdam Sentence

Corpus (Kliegl et al., 2004)

\section{4}

Range: 5-11 words, $M=7.9$

1,138 words

850 (without first and last words)

Range: 2-20

$M=5.5, M d n=5$ (all words)

$\mathrm{M}=7^{\dagger}$

83

Target words: $\quad$ All words:

$1-0$

$2-54$

$3-222$

$4-134$

$5-147$

$6-129$

$7-92$

$8-72$

$9-66$

$10-20$

$11-25$

$12-16$

$13-17$

$13+-7$

Class 1 (1-10 ipm $\left.{ }^{\dagger \dagger}\right)-$

Class $2(11-100 \mathrm{ipm})$ - $\quad 207$

Class $3(101-1,000)-\quad 242$

Class $4(1,001-10,000)-\quad 227$

Class 5 (10,001-max) -

$M=18 \%, M d n=5 \%$

Class $1(-2.553$ to -1.5$)-$

Class $2(-1.5$ to -1.0$)-$

Class $3(-1.0$ to -0.5$)-\quad 114$

Class $4(-0.5$ to 0$)-\quad 88$

Class 5 ( 0 to 2.553$)-\quad 175$

${ }^{\dagger}$ Empty cells for the PSC mean that no data are reported in Kliegl et al. (2004; Kliegl et al., 2006). ${ }^{\dagger \dagger}$ Items per million.

with the EyeLink 1000+ desktop mount eyetracker using a chin rest. They were seated at a comfortable distance of $55 \mathrm{~cm}$ from the camera and $90 \mathrm{~cm}$ from the monitor. In this setup, one character subtended $0.29^{\circ}$ visual angle. Only the right eye was tracked, at a rate of $1000 \mathrm{~Hz}$. Calibration consisting of nine points was performed before the beginning of the experiment and after every 15 sentences afterward.
Each trial began with a fixation point at the position of the first letter of the first word in the sentence. If the participant fixated it for at least $500 \mathrm{~ms}$, the sentence presentation automatically commenced; otherwise, after $2 \mathrm{~s}$ the 9-point calibration was repeated. Sentences were presented in one line in the middle of the screen against light gray background. After finishing reading the sentence, participants were instructed to look at the red dot 
in the lower right-hand corner of the screen. To ensure that participants read the sentences for comprehension, $33 \%$ of them were followed by an easy three-choice comprehension question; the response was recorded from a mouse click. Accuracy was always above $80 \%$. The program advanced to the next trial after a 1-s delay.

\section{Data analyses}

The data from all participants, regardless of their accuracy in answering the comprehension questions, were included. The eye movement data were split into fixations and saccades on the basis of the algorithm from the Data Viewer package (SR Research Ltd). The first and last words in every sentence were excluded from the analyses. The analyses were modeled on the ones used for the PSC in German (Kliegl et al., 2004); however, we used (generalized) linear mixed models $[(\mathrm{G}) \mathrm{LMMs}]$ instead of repeated measure multiple regressions using $\mathrm{R}$ ( $\mathrm{R}$ Core Team, 2016) and ggplot2 (Wickham, 2016). (G)LMMs were estimated with lme4 package, version 1.1-8 (Bates, Maechler, Bolker, \& Walker, 2015), partial effects were modeled with remef package (Hohenstein \& Kliegl, 2017), and the comparison table for (G)LMM outcomes (Table 5 below) was created with the sjPlot package (Lüdecke, 2017).

The (G)LMMs included varying intercepts for participants, sentences, and individual words. Fixed effects were estimated for the following variables: (a) centered and scaled word form length (linear and quadratic trends), (b) logarithm (base 10) of word form frequency (as taken from the StimulStat database), and (c) logittransformed predictability. The effects of the variables were estimated for nine dependent variables: four measures of reading time (i-iv) and five probabilities relating to skipping, fixating, or regression to or from words (v-ix):

i. first fixation duration (FFD);

ii. single fixation duration (SFD);

iii. gaze duration (GD);

iv. total reading time (TT);

v. probability of skipping the word ( $\mathrm{P} 0$ );

vi. probability of fixating the word only once (P1);

vii. probability of fixating the word more than once (P2);

viii. probability of regression to the previous words from the current word (RO);

ix. probability of regressing back to the word from the following words (RG).

To ensure the normal distribution of model residuals, durations (FFD, SFD, GD, and TT) were log-transformed. Binary dependent variables $(\mathrm{P} 0, \mathrm{P} 1, \mathrm{P} 2, \mathrm{RO}$, and $R G$ ) were fit with GLMMs with a logistic link function. There was no excessive collinearity of model predictors, since the variance inflation factor (VIF) for each of them was less than 5 .

The sentences, the eye movement data, and the script used for the analyses reported below are available at the Open Science Framework project page: https://osf.io/ $\mathrm{x} 5 \mathrm{q} 2 \mathrm{r} /$.

\section{Replication results: Similarities between the RSC and PSC}

\section{RSC: Descriptive characteristics of the materials}

Table 1 presents a comparison of the descriptive characteristics of the materials (for all sentences, corpus words, and target words) from the RSC and the PSC. The Russian sentences were longer than the German ones; therefore, the RSC contains 224 more words than the PSC. Since Russian possesses a number of highly frequent short words (one or two characters long), there were many more short words in the RSC, but the proportion of short words (one to four characters) was lower in the RSC (35\%) than in the PSC (41\%). The word frequency distributions were also different across the corpora: The RSC had $61 \%$ low- (1-100 ipm), 16\% average-, and $23 \%$ high-frequency words (for the PSC, these numbers were $45 \%, 24 \%$, and $30 \%$, respectively). Word predictability was measured as the number of correct guesses divided by the total number of guesses, and the distributions were quite comparable in the two corpora: The RSC had $65 \%$ words with low predictability, 9\% with average, and $23 \%$ with high (PSC: $66 \%, 11 \%$, and 26\%). The part-of-speech composition for the entire RSC was 468 nouns (34\%), 282 verbs (21\%), 126 adjectives (9\%), 52 adverbs (4\%), and $434(32 \%)$ pronouns and function words (no data are available for the PSC).

\section{RSC: Benchmark statistics of eye movements in reading in Russian}

The entire RSC consists of 1,362 words, with the first and last words of every sentence excluded from the analysis, resulting in 1,074 words. Figure 1 presents the four average fixation duration measures (measures $\mathrm{i}-\mathrm{iv}$ ) and their confidence intervals as a function of a word's length, frequency, and predictability (Figs. 1A$1 C$ ). The means (with $S D$ ), aggregated by participants, are as follows: SFD (blue line), 228 (26) ms; FFD (lilac line), 217 (23) ms; GD (green line), 259 (42) ms; TT (red line), 318 (79) $\mathrm{ms}$.

Figure 2 illustrates the mean proportions and confidence intervals of skipping (P0) or fixating a corpus 


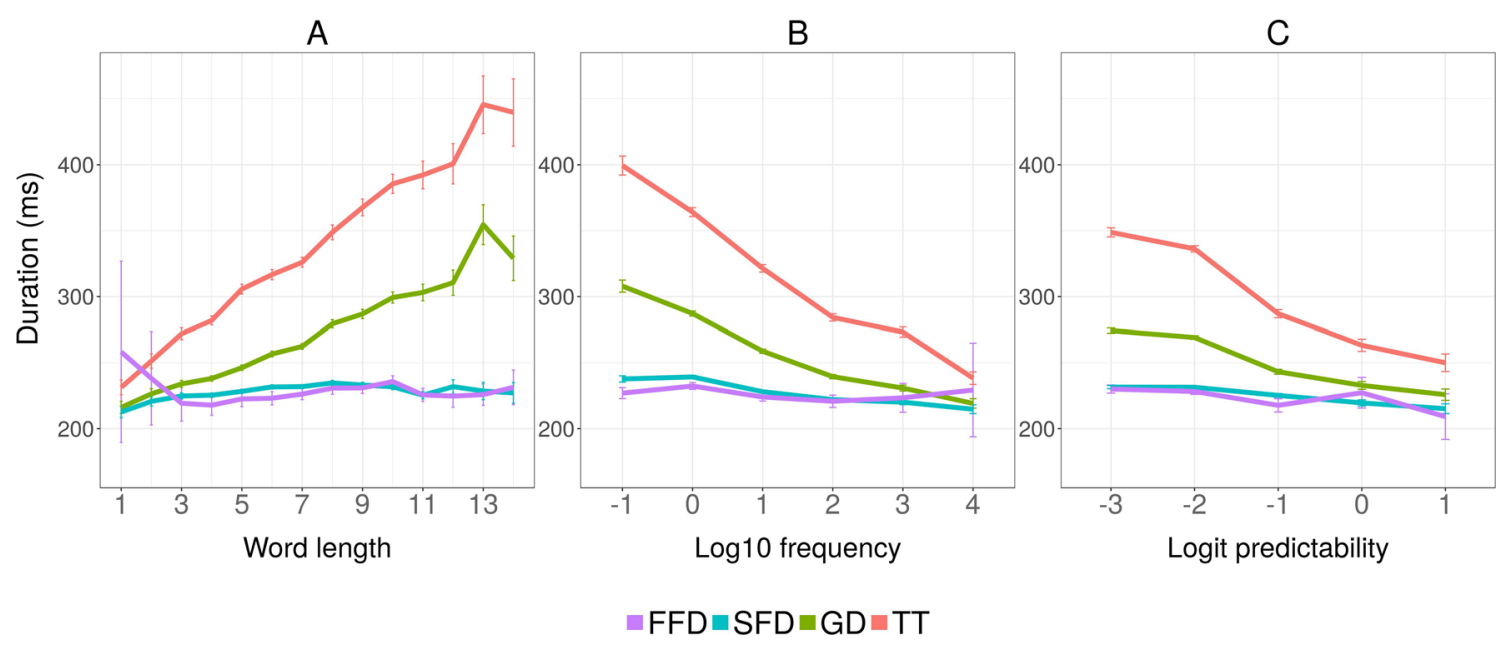

Fig. 1 All analyzed corpus words in the RSC $(n=1,074)$ : Means and 95\% CIs for four fixation duration measures (FFD, SFD, GD, TT) as a function of word length (A), log-transformed frequency (B), and logit-transformed predictability (C).

word ( $\mathrm{P} 1$ and $\mathrm{P} 2$, measures $\mathrm{v}$-vii) as a function of the word's length (A), frequency (B), and predictability (C). One third of all the corpus words in the RSC were skipped (34\%), and this rate is consistent with the 3035\% skipping rate reported for English (Rayner, 1998). Half of the words were fixated once $(56 \%)$, which is, again, highly consistent with the rate of single fixations reported for German, 57\% (Heister, Würzner, \& Kliegl, 2012). The remaining $9 \%$ of words were fixated two or more times. The means are different from the model predictions in Table 2 because the intercept of the model represents predictions for words of average length, a frequency of $1 \mathrm{ipm}$, and $50 \%$ predictability, whereas the mean skipping rate provided here is computed over all corpus words.
Finally, for the saccade measures (RO and RG, viii and ix), $13 \%$ of the corpus words were regressed to from the following regions, and $17 \%$ served as the origin of a regressive saccade. Similar to other alphabetic languages, the average saccade length in the RSC spans eight character spaces, with the saccades landing in the first half of the word, close to the word center (.43 of the word's length, where 0 represents the beginning and 1 the end of the word).

\section{Comparison with the PSC}

Table 2 summarizes the comparisons between the RSC and the PSC. The analysis of all corpus words (top part of Table 2) shows that most of the basic effects reported in the PSC for German were also replicated in the RSC for
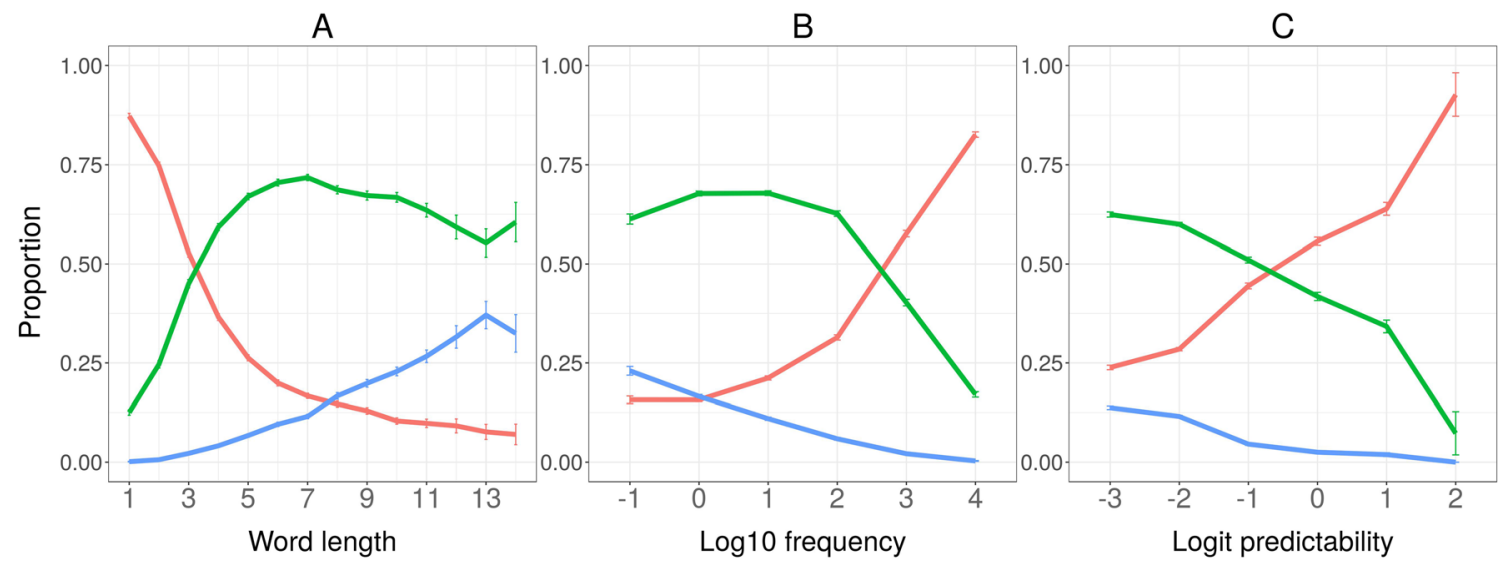

Skipped Fixated once Fixated twice +

Fig. 2 All analyzed corpus words in the RSC $(n=1,074)$ : P0, P1, and P2+ as a function of (A) word length, (B) log-transformed word frequency, and $(\mathrm{C})$ logit-transformed predictability. 
Table 2 All corpus $(n=1218)$ and target $(n=144)$ words (controlled for length and frequency) in the RSC: Basic benchmarks of eye movements in reading in Russian as compared to German

\section{Russian Sentence Corpus}

(this study)

\section{Potsdam Sentence Corpus}

(Kliegl et al. 2004)

\begin{tabular}{|c|c|c|c|c|c|c|c|c|c|c|}
\hline \multicolumn{11}{|c|}{ All Corpus Words } \\
\hline & Constant & Length & Length $^{2}$ & Freq & Pred & Constant & Length & Length $^{2}$ & Freq & $\overline{\text { Pred }}$ \\
\hline$\overline{\mathrm{FF}}$ & 222 & 2.8 & -0.1 & -4.5 & 0.5 & 207 & 1.5 & 0.3 & -5.4 & -3.2 \\
\hline$\overline{\mathrm{SF}}$ & 232 & 2.7 & -0.5 & -9.5 & -4.5 & 210 & 3.3 & 0.5 & -6.3 & -5.3 \\
\hline$\overline{\mathrm{GD}}$ & 231 & 7 & -0.5 & -14.8 & -6 & 241 & 8.5 & 0.5 & -11.8 & -10.3 \\
\hline$\overline{\mathrm{TT}}$ & 283 & 11.3 & -1.33 & -18.7 & -13.3 & 245 & 7.4 & -0.1 & -14.5 & -17.5 \\
\hline$\overline{\mathrm{P} 0}$ & 17.8 & -5.4 & 0.56 & 1.8 & 0 & 9.1 & -3.4 & 0.8 & 2.3 & 1.8 \\
\hline$\overline{\mathrm{P} 1}$ & 68.8 & 4.7 & -0.9 & -0.2 & 0.6 & 74.1 & -0.6 & -1.0 & 0.7 & 0.9 \\
\hline$\overline{\mathrm{P} 2+}$ & 4.9 & 2.0 & -0.08 & -0.99 & -1.1 & 17.0 & 4.1 & 0.2 & -2.5 & -2.6 \\
\hline$\overline{\mathrm{RO}}$ & 17.8 & -1.9 & 0.9 & -1.3 & 2.9 & 12.5 & -0.6 & -0.3 & -0.8 & $\overline{0.0}$ \\
\hline$\overline{\mathrm{RG}}$ & 7 & -1.3 & 0.7 & -0.2 & -1.4 & 0.4 & -1.0 & -0.1 & -0.7 & -3.7 \\
\hline
\end{tabular}

Target Words

\begin{tabular}{lcccccccccr}
\hline FF & 207 & $\mathbf{2}$ & $\mathbf{- 0 . 1 5}$ & -1.5 & -0.9 & 214 & 0.4 & $\mathbf{0 . 3}$ & $\mathbf{- 4 . 5}$ & 1.2 \\
\hline SF & 225 & $\mathbf{1}$ & $\mathbf{- 0 . 1 7}$ & $\mathbf{- 5}$ & -0.7 & 213 & $\mathbf{1 . 6}$ & $\mathbf{0 . 6}$ & $\mathbf{- 4 . 1}$ & -0.5 \\
\hline GD & 251 & $\mathbf{5}$ & 0.2 & $\mathbf{- 8 . 6}$ & $\mathbf{- 3}$ & 247 & $\mathbf{9 . 1}$ & $\mathbf{2 . 0}$ & $\mathbf{- 8 . 1}$ & -3.5 \\
& & & & & & & & & & \\
\hline TT & 276 & $\mathbf{9}$ & 0 & $\mathbf{- 1 3}$ & $\mathbf{- 7}$ & 253 & $\mathbf{9 . 1}$ & $\mathbf{1 . 9}$ & $\mathbf{- 9 . 5}$ & $\mathbf{- 7 . 3}$
\end{tabular}

\begin{tabular}{lllllllllll}
\hline P0 & 14.9 & $\mathbf{- 9 . 8}$ & $\mathbf{5 . 7}$ & $\mathbf{2 . 5}$ & $\mathbf{1 . 6 8}$ & 7.1 & $\mathbf{- 4 . 6}$ & $\mathbf{0 . 8}$ & $\mathbf{3 . 0}$ & $\mathbf{1 . 7}$
\end{tabular}

\begin{tabular}{lllllllllll}
\hline P1 & 70.4 & $\mathbf{9 . 6}$ & $\mathbf{- 8 . 3}$ & 0.1 & -1.2 & 76.2 & 0.4 & $\mathbf{- 1 . 4}$ & $\mathbf{- 1 . 8}$ & -0.1
\end{tabular}

\begin{tabular}{lllllllllll}
\hline $\mathrm{P} 2+$ & 6.7 & $\mathbf{1 0 . 6}$ & $\mathbf{- 1 . 3}$ & $\mathbf{- 1 . 7}$ & $\mathbf{- 0 . 9}$ & 16.4 & $\mathbf{4 . 2}$ & $\mathbf{0 . 5}$ & $\mathbf{- 1 . 2}$ & $\mathbf{- 1 . 7}$
\end{tabular}

\begin{tabular}{lcccccccccr}
\hline RO & 14.7 & $\mathbf{- 2 . 8}$ & 0 & -1.1 & 0 & 7.3 & 0.0 & 0.0 & $\mathbf{- 0 . 6}$ & $\mathbf{- 1 . 8}$ \\
\hline RG & 5.5 & $\mathbf{- 1 . 4}$ & $\mathbf{0 . 6}$ & -0.1 & $\mathbf{- 1 . 2}$ & 0.2 & $\mathbf{- 1 . 0}$ & $\mathbf{0 . 1}$ & 0.5 & $\mathbf{- 2 . 5}$
\end{tabular}

The cells in which the effects pattern differently between the RCS and PCS are shaded in grey. Significant effects are in bold. The first four fixation duration measures (FF, SF, GD, TT) are in ms, the rest are probabilities. 
Russian, with a few differences (differences between the $\mathrm{RSC}$ and PSC that manifested in the presence/absence of a certain effect or in its direction are shaded in gray). The first such difference is that in Russian, but not in German, P1 increases with the increase in word's length and predictability. The explanation may be trivial: In Russian, if a word is not fixated once, it is more likely to be skipped than to be fixated more than once (see Fig. 2), whereas in German the opposite is true. This means that in the RSC we are comparing words that were fixated once with those that were skipped, and longer words are more often fixated than skipped. The second difference is less clear: Higher predictability increases P1 in Russian, but this effect was not significant in German. Theoretically, higher predictability should increase the probability of skipping, and this trend is present in the analysis of the target words in Russian. It is possible that the fact that as a word's predictability increases, its probability of being fixated also increases is due to the lower correlation between the word's length and frequency, or word position in the sentence (as compared to German), yielding better statistical power for this positive predictability effect in Russian.

Finally, for the regression measures, the probability that a word is the origin of a regression (RO) does not depend on any of the parameters in German, whereas in Russian it increases with word predictability and decreases when word length and frequency increase. However, only the length effect remains constant for the target words, so the frequency and predictability influence might once again have to do with the length and frequency correlations of all corpus words. We leave the explanation of this pattern of results for future research.

For the target words $(n=144$; Table 2, bottom part), when length and frequency are controlled, the relationships between the basic word parameters and dependent measures are also very close to those for the PSC in German: As the frequency and predictability of a target word increase, the reading times decrease (all measures), and as the target word length increases, the reading times also increase.

There were some minor differences in the timing of these effects. First, in Russian, the target word length affects all fixation duration measures (i.e., FFD, SFD, GD, and TT) whereas FFD was not affected in German. Second, predictability in Russian affects both GD and TT, but only TT in German. These effects might have a trivial explanation: in the analysis by Kliegl et al. (2004), data from 65 participants were included, whereas the materials of the RSC were read by 96 participants. It is possible that higher statistical power allowed us to detect the effects of smaller size in the "earlier" duration measures. Third, in Russian, FFD and P1 do not depend on word frequency; in German, frequency affects all eye movement measures.

The most notable difference between the two corpora with respect to the target words is the influence of the square of a word's length (Length $^{2}$ in Table 2, which exaggerates the difference between short and long words): In German, an increase in length ${ }^{2}$ leads to increases in FFD, SFD, GD, TT, and $\mathrm{P} 2+$, whereas in Russian, the opposite is often true. That is, in Russian, longer words do not attract longer fixation durations; moreover, there is a tendency for fixation durations to get shorter for longer words. At the moment, pending future exploration of the RSC, we hypothesize that this difference has to do with the predictability of morphological markings in Russian. Longer words contain more affixes, and because they can be anticipated in the sentential context, skilled readers take advantage of this anticipatory information by spending less time on longer words with affixes. An alternative explanation concerns reading proficiency: Kuperman and Van Dyke (2011) demonstrated that for more proficient readers, the correlation between the word's length and reading time was weaker than for lower-skilled readers; that difference between readers was most apparent in reading times for longer words. Since the majority of our sample were skilled readers (i.e., university students), the difference between corpora might be explained by individual differences between readers and not languages.

\section{The impacts of the previous and upcoming words on single fixation durations}

Finally, to see how the properties of the previous and upcoming words influence the SFD on the current word in Russian and German, we compared the data from the RSC with multiple regression analysis from Kliegl et al. (2006). The most notable differences between the corpora concern the effects of the previous, current, and upcoming words' lengths on SFD, shown in Table 3.

The current word In contrast to the well-established length effects in English and German, in Russian the current word's length does not affect SFD. One possible explanation is that the word that was fixated once was already anticipated before the saccade was launched to it; in this case, the single fixation serves to check whether the prediction was correct and does not require the reader to fully process the word. Or again, the individuals that read sentences for the RSC may be more proficient readers who could quickly recognize whole word forms, which led to their reading times being less affected by word length. Finally, the relationship between frequency, predictability, and single-fixation duration was as predicted: As in other languages, increases in frequency and predictability decreased SFD on the word.

The previous word ( $\mathbf{n}-1)$ The previous word's length does not affect SFD in Russian, in contrast to German. Another difference from German concerns predictability: An increase in the predictability of the previous word increases rather than 
Table 3 All analyzed corpus words $(n=1,074)$ : Predicted single-fixation duration (SFD, measured in milliseconds) as a function of the previous, current, and the next words' frequency, predictability, and length

Russian Sentence Corpus

(this study)
Potsdam Sentence Corpus

(Kliegl et al. 2006)

\begin{tabular}{|c|c|c|}
\hline & \multicolumn{2}{|c|}{ Current Word } \\
\hline Constant & 225 & 208 \\
\hline Frequency & -5.5 & -4.6 \\
\hline Predictability & -1.7 & -5 \\
\hline \multirow[t]{2}{*}{ Length } & $0.05^{\dagger \dagger}$ & 55 \\
\hline & \multicolumn{2}{|c|}{ Previous Word } \\
\hline Frequency & -1.23 & -5.1 \\
\hline Predictability & 1.93 & -1.6 \\
\hline Length & 1.05 & 15 \\
\hline
\end{tabular}

Following Word

\begin{tabular}{lcc}
\hline Frequency & $\mathbf{- 3 . 6}$ & $\mathbf{- 2 . 5}$ \\
Predictability & $\mathbf{3 . 2}$ & $\mathbf{1 . 9}$ \\
Length & $\mathbf{- 5 . 7}$ & -1.2 \\
\hline Incoming saccade amplitude & $\mathbf{2 . 1 1}$ & $\mathbf{4 . 7}$ \\
\hline Saccade landing position & $\mathbf{- 2 . 8}$ & $\mathbf{- 7 . 7}$
\end{tabular}

The cells in which the effects pattern differently between the RCS and PCS are shaded in grey.

$\dagger$ Some of the models reported in Kliegl et al. (2006) included additional predictors and interactions between those predictors.

$\dagger \dagger$ In Kliegl et al. (2006), word length was reciprocally transformed. In our analysis, it was centered and scaled. It follows that the effect size estimates are on different scales and not directly comparable.

decreases the SFD on the current word in Russian. This might be explained by more predictable words being skipped more often, since fixations following word skipping are known to be longer.

The upcoming word $(\mathbf{n}+1)$ We also found that in Russian, but not in German, increases in length of the upcoming word decreased reading times on the current one. We tentatively attribute these faster reading times to distributed word processing: Russian readers process the upcoming word parafoveally when it is short (thus spending more time fixating the current word), and in the fovea when it is long (thus making a saccade to the upcoming word and spending less time on the current word). This strategy confirms the other replicated effects that speak in favor of distributed word processing: Both the negative $n+1$ frequency and positive $n+1$ predictability effects that were previously found (Fernández et al., 2014; Kliegl et al., 2006; Laubrock \& Kliegl, 2015; Schad, Nuthmann, \& Engbert, 2012) were significant. Although the idea of the distributivity of lexical processing across several words during reading is debated (Rayner, Pollatsek, Drieghe, Slattery, \& Reichle, 2007), at least for Russian, the negative $n+1$ frequency and positive $n+1$ predictability effects, as well as the negative $n+1$ length effect, all strongly support distributed lexical processing. 


\section{Novel results: Exploitation of the RSC}

To demonstrate a broader range of potential applications of the $\mathrm{RSC}$, we used it in three small exploratory investigations of how eye movements in reading in Russian are influenced by the most prominent characteristic of the Russian languagethat is, its morphology. The analyses reported below used LMMs that were based on two sets of predictors: the ones used for the comparisons between RSC and PSC (i.e., the length, frequency, and predictability of the previous, current, and the upcoming words, as well as the amplitude of the incoming saccade and the saccade landing position; see Table 3 above) and three novel morphological predictors, namely the part-of-speech (PoS) category, morphosyntactic ambiguity, and morphological word form (base vs. nonbase). We also controlled for the relative position of the word in the sentence, an important predictor of reading speed (Kuperman, Dambacher, Nuthmann, \& Kliegl, 2010). The comparison between the models is presented in Table 4. The full summary of the models is presented in Table $\mathbf{5}$ of Appendix B.

\section{Part-of-speech (PoS) category}

Research on lexical processing has found that verbs are often more difficult to process than nouns: They are acquired later (Bassano, 2000), take a longer time to produce (Szekely et al., 2005), induce higher processing-based activation in neuroimaging studies (Crepaldi, Berlingeri, Paulesu, \& Luzzatti, 2011), and in aphasia are more impaired in naming (Jonkers \& Bastiaanse, 1996; Mätzig, Druks, Masterson, \& Vigliocco, 2009) than nouns. We hypothesized that verbs should be read more slowly than nouns in Russian. Indeed, Fig. 3 shows that the fixation durations are longer for the verbs than for the other parts of speech in the RSC.

Adding the part-of-speech predictor significantly improved the fit of the models for SFD, GD, and TT (see Table 4), and statistical analysis confirmed that verbs are read slower than nouns in the GD and TT measures (see Table 5, Appx. B). Words belonging to the other parts of speech (i.e., adjectives, adverbs, and function words) did not differ significantly from the verbs in any of the eye-tracking measures: The numerical difference in mean reading times is most likely accounted for by low-level parameters, such as frequency, length, and predictability. The difference between nouns and verbs, however, cannot be fully explained by these parameters. Thus, our findings confirm that verb processing requires more effort than noun processing, and they do so in one of the most ecologically valid setups - that is, when verbs and nouns are embedded into natural sentences.

\section{Morphosyntactic ambiguity}

Research on lexical ambiguity in English has revealed that reading times increase at ambiguous words if the two meanings of the word are equally probable or if the context favors the less frequent meaning. But to the best of our knowledge, it is not known whether morphosyntactic ambiguity would influence reading times in the same way. Morphosyntactic ambiguity, in the form of case syncretism on the noun (and its modifiers), is ubiquitous in Russian, because this language has an elaborate nominal system with six grammatical cases and three declension classes. One morpheme (e.g., -i) can represent different cases as well as be used to convey syncretic information about the grammatical

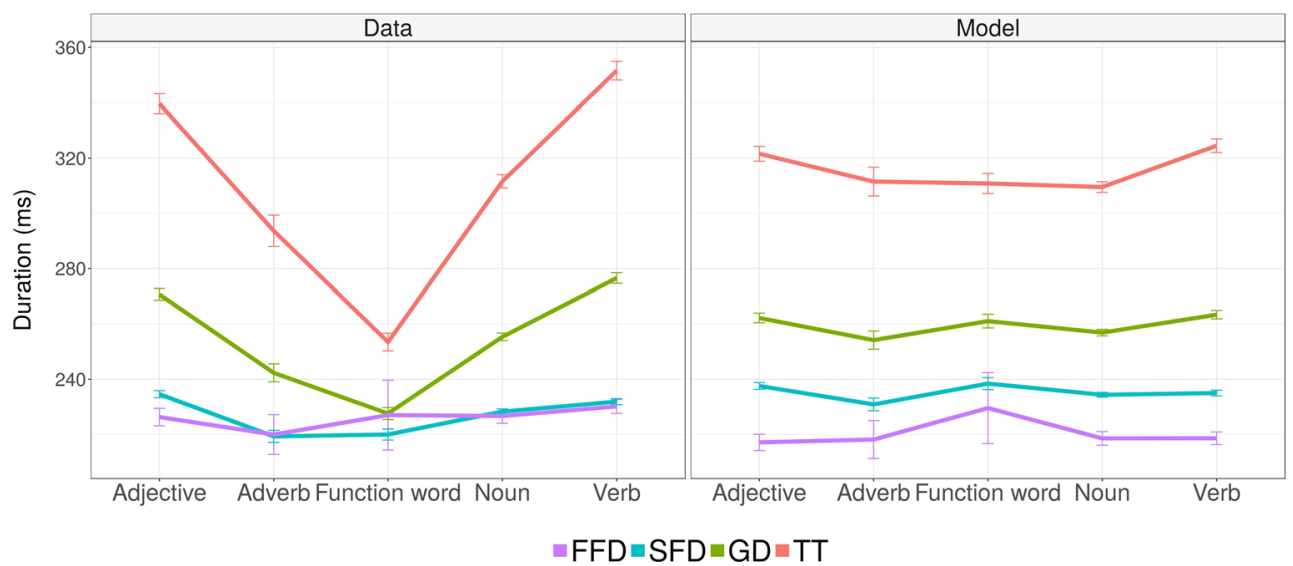

Fig. 3 All corpus words in the RSC ( $n=1,074)$ : Means and 95\% CIs for the four duration measures as a function of part-of speech category (adjectives, adverbs, function words, nouns, and verbs). The left panel shows the empirical means, and the right panel, partial effects from the mixed-effects model. 
Table 4 Comparison between the basic model (Comparison with the PSC section) and models including additional parameters of interest

\begin{tabular}{|c|c|c|c|c|}
\hline & FFD & SFD & GD & TT \\
\hline Basic model & 1,348 & -716 & 39,732 & 75,667 \\
\hline $\begin{array}{l}+ \text { Word position } \\
\text { in the sentence }\end{array}$ & $\begin{array}{l}\mathbf{1 , 3 3 3} \\
\chi^{2}(1)=16.9\end{array}$ & $\begin{array}{l}-\mathbf{8 9 8} \\
\chi^{2}(1)=184\end{array}$ & $\begin{array}{l}39,606 \\
\chi^{2}(1)=127\end{array}$ & $\begin{array}{l}\mathbf{7 5 , 6 6 4} \\
\chi^{2}(1)=104\end{array}$ \\
\hline & All $p s<.0001$ & & & \\
\hline+ Part of speech & $\begin{array}{l}1,339 \\
\chi^{2}(4)=2.25 \\
p>.05\end{array}$ & $\begin{array}{l}-\mathbf{9 0 2} \\
\chi^{2}(4)=12 \\
p=.017\end{array}$ & $\begin{array}{l}\mathbf{3 9 , 5 9 8} \\
\chi^{2}(4)=16 \\
p=.003\end{array}$ & $\begin{array}{l}\mathbf{7 5 , 5 4 7} \\
\chi^{2}(4)=25 \\
p<.0001\end{array}$ \\
\hline + Morphosyntactic ambiguity & $\begin{array}{l}1,341 \\
\chi^{2}(1)=0.12\end{array}$ & $\begin{array}{l}-902 \\
\chi^{2}(1)=1.75\end{array}$ & $\begin{array}{l}39,599 \\
\chi^{2}(1)=1.15\end{array}$ & $\begin{array}{l}75,549 \\
\chi^{2}(1)=0.16\end{array}$ \\
\hline $\begin{array}{c}+ \text { Base/nonbase } \\
\text { word form }\end{array}$ & $\begin{array}{l}\text { All } p \mathrm{~s}>.05 \\
\mathbf{1 , 3 3 8} \\
\chi^{2}(1)=4 \\
p=.044\end{array}$ & $\begin{array}{l}-903 \\
\chi^{2}(1)=3.5 \\
p>.05\end{array}$ & $\begin{array}{l}39,598 \\
\chi^{2}(1)=3.4 \\
p>.05\end{array}$ & $\begin{array}{l}\mathbf{7 5 , 5 4 6} \\
\chi^{2}(1)=4.7 \\
p=.03\end{array}$ \\
\hline
\end{tabular}

Each cell contains the value of the Akaike information criterion (AIC) for the given model. Cells with predictors added to the basic model contain the results of comparison to the simpler model in the row above: the value of the $\chi^{2}$ statistic and the corresponding $p$ value. Significant improvements over simpler model are in bold.

case, gender, and number (Baerman, Brown, \& Corbett, 2005, chap. 5). In the RSC, $35 \%$ of all words were ambiguous with respect to morphosyntactic form. For example, the word аварии "car accident(s)" is morphosyntactically ambiguous between 'car accidentPREP/DAT/GEN. SG' and 'car accident-NOM/ACC. PL'. Within the sentence, the majority of these ambiguous morphosyntatic forms are disambiguated by context, but we hypothesized that they might be processed slower, just as with lexical ambiguity. Figure 4 demonstrates that the morphosyntactically ambiguous word forms in the RSC were read numerically slower than the unambiguous ones.

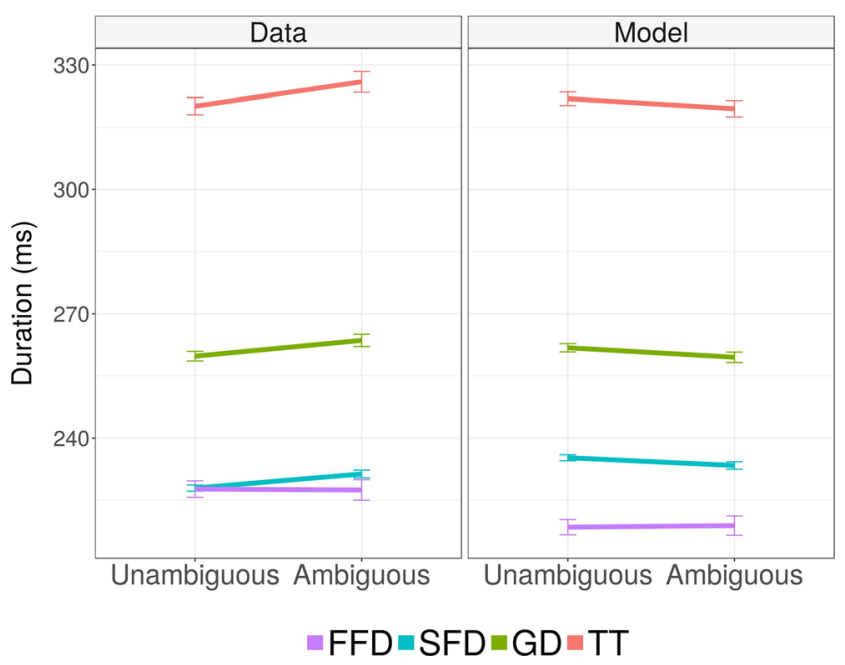

Fig. 4 All analyzed corpus words $(n=1,074)$ : Means and 95\% CIs as a function of morphosyntactic ambiguity. The left panel shows the empirical means, and the right panel, partial effects from the mixed-effects model.
However, adding morphosyntactic ambiguity as a predictor did not improve the fit of any of the time duration models (see Table 4). It follows that in the LMMs, there was no evidence for a difference in reading times between morphosyntactically ambiguous and unambiguous word forms in the RSC (see Table 5, Appx. B). We attribute this apparent divergence between the means and the model estimates to the fact that the model accounts for the influences of the previous, current, and upcoming words' length, frequency, and predictability. The observed difference in the mean reading times between the ambiguous and unambiguous word forms may be better explained by these parameters.

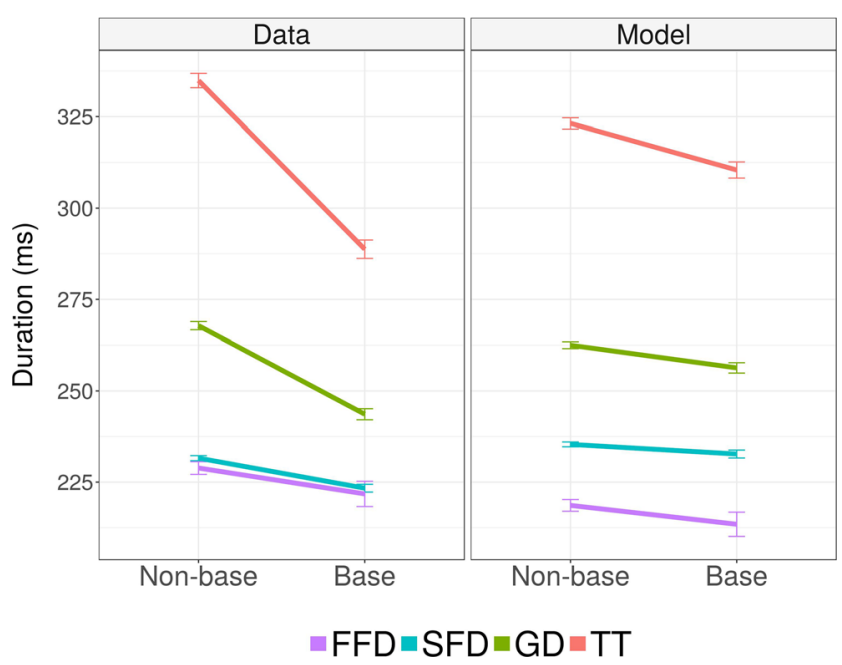

Fig. 5 All corpus words $(n=1,074)$ : Means and 95\% CIs as a function of base/nonbase word form. The left panel shows the empirical means, and the right panel, partial effects from the mixed-effects model. 


\section{Base versus nonbase word form}

The last question we explored concerned reading times for words in their base form (corresponding to the dictionary form; e.g., the NOM. SG case for nouns, and the infinitive for verbs) as compared to their nonbase forms (other cases for nouns and conjugated forms for verbs). Russian nouns have 12 inflectional forms (6 cases $\times 2$ numbers). Russian verbs, likewise, belong to two conjugational classes and bear grammatical markings for person and number (as well as gender, in the past tense). In addition, Russian grammatical markers are always syncretic (see Morphosyntactic ambiguity section). This proliferation of inflected forms to a greater degree is also found in Finnish; however, Finnish is an agglutinative language in which one morphological marker corresponds to one grammatical feature, and it does not display morphosyntactic ambiguity in the form of syncretism, the way Russian does.

Reading in Finnish has been studied extensively, and, in particular, a lot of attention has been paid to the reading of inflected and compound word forms. Hyönä et al. (1995) found that in reading isolated Finnish words, inflected forms attracted longer first and second fixation durations than words in their base form. We were interested to see whether the same effect would be present in Russian for words in their base versus nonbase forms (note that most base forms are inflected in Russian, in contrast to Finnish). In the RSC, 34\% of all words were in their base form, and the mean fixation durations were higher for the non-base-form words (Fig. 5).

Adding a predictor differentiating the base and nonbase word forms significantly improved the fit of the models for FFD and TT (see Table 4). Nonbase word forms indeed took longer to read, and the effect was significant in the FFD and TT measures (see Table 5, Appx. B). However, given that no other lexical measures influenced FFD, the influence of word form on FFD is likely to be a Type I error. We leave this intriguing question of whether base word forms are easier to process universally for a future investigation of morphological factors in Russian.

\section{Conclusion}

The main goal of this article was to introduce the new Russian Sentence Corpus of eye movements during sentence reading in a Slavic language with a Cyrillic script - that is, Russian, which has not yet been investigated in cross-linguistic eye movement research. As in every language studied so far, we have confirmed the expected effects of low-level parameters, such as word length, frequency, and predictability, on the eye movements of skilled Russian readers. The findings from our study allow us to add Cyrillic-based Slavic languages to the growing number of languages with different orthographies ranging from the Roman-based European languages to logographic Asian ones whose eye movement benchmarks confirm the universality of basic benchmarks in reading (Share, 2008). We have also established descriptive corpus statistics for reading in Russian in the form of the average saccade length, landing site, fixation duration measures, probabilities of skipping and fixating words, as well as proportions of regressions, in reading of natural sentences. Finally, we have conducted three simple exploratory investigations of the effects of morphology on the basic eye movement measures in Russian that illustrate the kinds of questions researchers can answer using the RSC.

We are confident that the RSC will be of particular use to the researchers interested in morphological processing because of rich inflectional and derivational morphology characteristics not only of Russian but of most Slavic languages. The novel feature of the RSC is its full morphological annotation-namely, full specification of the morphemes that compose each word. Currently the Russian Sentence Corpus has the following levels of annotation: (i) morpheme annotation (number and identity of word's affixes, annotated manually on the basis of the Word Formation Dictionary by A. N. Tikhonov (2003); (ii) disambiguated morphological annotation (part of speech and grammatical characteristics for each part of speech), performed with mystem2 (https://tech.yandex.ru/ mystem/) and validated manually; (iii) syntactic annotation in the terms of dependency grammar (according to the Universal Dependencies guidelines: http:// universaldependencies.org); (iv) phonetic stress annotation; and (v) semantic annotation-that is, the number of meanings according to Efremova (2000). The annotated corpus is freely available at https://osf.io/ $55 \mathrm{q} 2 \mathrm{r} /$.

The effects of morphosyntactic information on eye movements in reading in fusional languages with pervasive syncretism like Russian differ from those in many Indo-European and agglutinative languages and wait to be explored, which may well result in the modification of existing theories of reading.

Author note The study has been funded by the Center for Language and Brain, NRU Higher School of Economics, RF Government Grant № 14.641.31.0004. Anna Laurinavichyute, Svetlana Alexeeva, and Kristine Bagdasaryan were also supported by the Russian Foundation for Humanities (Russian Foundation for Basic Research) grant №17-34-01052, which enabled collection of eye-movements from 30 participants as well as the full annotation of corpus materials. 


\section{Appendix A: Sample sentences from the RSC}

Target words are in bold.

1. Не поручайте мужу ухаживать за рыбками в аквариуме, он обязательно забудет.

Do not entrust the aquarium fish to your husband, he is certain to forget all about them.

2. Сделав мне знак помолчать, он приложил ухо к двери.

Prompting me to keep silent, he pressed his ear to the door.

3. Дорога ведет в глухой лес, петляя по склонам.

The road leads to the dense forest, winding along the slopes.

4. Мне было лень идти на стоянку и сметать снег с машины.

I was too lazy to go to the parking lot and clean the snow off the car.

5. Если мы позволим этим людям уйти, наши проекты станут гораздо беднее.

If we let these people go, our projects will be impoverished.

6. Тема эта в то время была новой для многих.

This topic was new for many people at that time.
7. Зоопарк - это кусочек другого мира, находящийся в самом центре нашего района.

Zoo is a piece of some other world right in the center of our district.

8. Чтобы придать объем тонким волосам, нанесите на них лечебную маску.

To add volume to thin hair, apply the healing mask.

9. Судя по огромному расходу воды, они купали слонов.

Judging by the enormous water consumption, they bathed elephants.

10. Володя каким-то образом узнал то, чего ему не надо было знать.

Volodya somehow learned what he should not have learned.

11. Мне нравится сын коллеги, который ${ }^{1}$ недавно заходил в наш отдел.

I like the son of the colleague who recently stopped by in our department.

12. Зачем ему звонить, если откликается спокойный женский голос?

Why call him, if a calm female voice answers the phone?

13. Но четыре года я не мог себя заставить сделать это. But for years ago I couldn't make myself do it.

\section{Appendix B}

Table 5 Summary of the LMMs for the duration measures: FFD, SFD, GD, and TT

\begin{tabular}{|c|c|c|c|c|c|c|c|c|c|c|c|c|}
\hline & \multicolumn{3}{|l|}{ Log FFD } & \multicolumn{3}{|l|}{ Log SFD } & \multicolumn{3}{|l|}{$\log$ GD } & \multicolumn{3}{|l|}{$\log \mathrm{TT}$} \\
\hline & Estimate & Std. Error & $p$ & Estimate & Std. Error & $p$ & Estimate & Std. Error & $p$ & Estimate & Std. Error & $p$ \\
\hline \multicolumn{13}{|l|}{ Fixed Effects } \\
\hline (Intercept) & 5.302 & 0.026 & $<.001$ & 5.301 & 0.018 & $<.001$ & 5.385 & 0.023 & $<.001$ & 5.499 & 0.033 & $<.001$ \\
\hline Log frequency & -0.007 & 0.004 & .138 & -0.023 & 0.003 & $<.001$ & -0.035 & 0.004 & $<.001$ & -0.048 & 0.005 & $<.001$ \\
\hline Logit predictability & -0.012 & 0.005 & .013 & -0.015 & 0.002 & $<.001$ & -0.022 & 0.003 & $<.001$ & -0.036 & 0.004 & $<.001$ \\
\hline Length & 0.009 & 0.003 & .001 & 0.003 & 0.001 & .034 & 0.018 & 0.002 & $<.001$ & 0.028 & 0.003 & $<.001$ \\
\hline Length squared & -0.001 & 0.000 & .034 & -0.001 & 0.000 & .002 & 0.001 & 0.000 & .006 & 0.000 & 0.000 & .653 \\
\hline$n+1$ length & -0.013 & 0.005 & .011 & -0.025 & 0.003 & $<.001$ & -0.033 & 0.004 & $<.001$ & -0.041 & 0.005 & $<.001$ \\
\hline$n+1 \log$ frequency & -0.002 & 0.004 & .594 & -0.012 & 0.002 & $<.001$ & -0.016 & 0.003 & $<.001$ & -0.021 & 0.004 & $<.001$ \\
\hline$n+1$ predictability & -0.006 & 0.004 & .090 & 0.003 & 0.002 & .137 & 0.002 & 0.003 & .520 & -0.008 & 0.004 & .027 \\
\hline$n-1$ length & -0.001 & 0.005 & .922 & 0.005 & 0.003 & .056 & -0.001 & 0.004 & .710 & -0.007 & 0.005 & .151 \\
\hline$n-1 \log$ frequency & -0.002 & 0.004 & .571 & -0.003 & 0.002 & .131 & 0.001 & 0.003 & .842 & 0.001 & 0.004 & .694 \\
\hline$n-1$ predictability & -0.002 & 0.004 & .564 & -0.002 & 0.002 & .402 & -0.003 & 0.003 & .223 & -0.011 & 0.004 & .003 \\
\hline $\begin{array}{l}\text { Word position in the } \\
\text { sentence }\end{array}$ & 0.071 & 0.017 & $<.001$ & 0.130 & 0.009 & $<.001$ & 0.137 & 0.012 & $<.001$ & 0.171 & 0.017 & $<.001$ \\
\hline Adjective & -0.005 & 0.012 & .658 & 0.009 & 0.008 & .220 & 0.000 & 0.010 & .972 & -0.000 & 0.015 & .996 \\
\hline Adverb & 0.002 & 0.020 & .932 & -0.019 & 0.012 & .107 & -0.026 & 0.016 & .099 & -0.030 & 0.023 & .186 \\
\hline Function word & 0.038 & 0.025 & .126 & 0.016 & 0.012 & .181 & 0.007 & 0.015 & .649 & -0.014 & 0.022 & .532 \\
\hline Noun & 0.000 & 0.009 & .975 & -0.005 & 0.006 & .378 & -0.017 & 0.008 & .031 & -0.039 & 0.011 & $<.001$ \\
\hline Ambiguity & 0.002 & 0.009 & .852 & -0.007 & 0.006 & .242 & -0.010 & 0.007 & .191 & -0.007 & 0.011 & .489 \\
\hline Base form & -0.021 & 0.010 & .048 & -0.009 & 0.006 & .141 & -0.015 & 0.008 & .069 & -0.025 & 0.012 & .031 \\
\hline $\begin{array}{l}\text { Incoming saccade } \\
\text { amplitude }\end{array}$ & -0.001 & 0.001 & .367 & 0.009 & 0.000 & $<.001$ & 0.006 & 0.000 & $<.001$ & 0.006 & 0.000 & $<.001$ \\
\hline
\end{tabular}

\footnotetext{
1 "Который” is a pronoun that takes adjective declension.
} 
Table 5 (continued)

\begin{tabular}{|c|c|c|c|c|c|c|c|c|c|c|c|c|}
\hline & \multicolumn{3}{|l|}{ Log FFD } & \multicolumn{3}{|l|}{ Log SFD } & \multicolumn{3}{|l|}{$\log$ GD } & \multicolumn{3}{|l|}{$\log \mathrm{TT}$} \\
\hline & Estimate & Std. Error & $p$ & Estimate & Std. Error & $p$ & Estimate & Std. Error & $p$ & Estimate & Std. Error & $p$ \\
\hline \multicolumn{13}{|l|}{ Random Effects } \\
\hline$\sigma^{2}$ & 0.065 & & & 0.056 & & & 0.101 & & & 0.171 & & \\
\hline$\tau 00$, word & 0.002 & & & 0.002 & & & 0.005 & & & 0.010 & & \\
\hline$\tau 00$, sentence & 0.000 & & & 0.001 & & & 0.001 & & & 0.003 & & \\
\hline$\tau 00$, participant & 0.008 & & & 0.014 & & & 0.022 & & & 0.043 & & \\
\hline Nwords & 749 & & & 778 & & & 778 & & & 778 & & \\
\hline Nsentences & 144 & & & 144 & & & 144 & & & 144 & & \\
\hline Nparticipants & 96 & & & 96 & & & 96 & & & 96 & & \\
\hline Observations & 8,746 & & & 55,772 & & & 68,725 & & & 68,725 & & \\
\hline $\mathrm{R}^{2} / \Omega 0^{2}$ & $.176 / .170$ & & & $.243 / .243$ & & & $.259 / .259$ & & & $.301 / .300$ & & \\
\hline
\end{tabular}

In the table, $n+1$ and $n-1$ represent the next and the previous words. The intercept represents the log-transformed mean duration of the corresponding measure, the predictors - adjustments to the intercept per unit change.

\section{References}

Ablinger, I., Huber, W., \& Radach, R. (2014). Eye movement analyses indicate the underlying reading strategy in the recovery of lexical readers. Aphasiology, 28, 640-657.

Alexeeva, S., Slioussar, N., \& Chernova, D. (2017). StimulStat: A lexical database for Russian. Behavior research methods, 1-11.

Alexeeva S. V., \& Slioussar, N. A. (2017). Effekt dliny pri parafoveal'noj obrabotke slov vo vrema chtenia [The effect of length in parafoveal processing of word in reading]. Tomsk State University Journal Filologia 45, 5-29.

Anisimov, V. N., Fedorova, O. V., \& Latanov, A. V. (2014). Eye movement parameters in reading sentences with syntactic ambiguities in Russian. Human Physiology, 40, 521-531.

Ashby, J., Rayner, K., \& Clifton, C. (2005). Eye movements of highly skilled and average readers: Differential effects of frequency and predictability. Quarterly Journal of Experimental Psychology, 58A, $1065-1086$

Baerman, M., Brown, D., \& Corbett, G. G. (2005). The syntax-morphology interface: A study of syncretism. New York, NY: Cambridge University Press.

Bai, X., Yan, G., Liversedge, S. P., Zang, C., \& Rayner, K. (2008). Reading spaced and unspaced Chinese text: Evidence from eye movements. Journal of Experimental Psychology: Human Perception and Performance, 34, 1277-1287. doi:https://doi.org/ 10.1037/0096-1523.34.5.1277

Bassano, D. (2000). Early development of nouns and verbs in French: Exploring the interface between lexicon and grammar. Journal of Child Language, 27, 521-559.

Bates, D., Mächler, M., Bolker, B., \& Walker, S. (2015). Fitting linear mixed-effects models using lme4. Journal of Statistical Software, 67, 1-48. doi:https://doi.org/10.18637/jss.v067.i01

Bezrukikh, M. M., \& Ivanov, V. V. (2012). Eye movements during reading as an indicator of development of reading skill. Fiziologiia Cheloveka, 39, 83-93.

Boston, M. F., Hale, J. T., Kliegl, R., Patil, U., \& Vasishth, S. (2008). Parsing costs as predictors of reading difficulty: An evaluation using the Potsdam sentence corpus. Journal of Eye Movement Research, 2(1):1-12. doi:https://doi.org/10.16910/jemr.2.1.1

Chernova, D. A. (2015). Eye-tracking study of attachment ambiguity resolution in Russian. Voprosy Psikholingvistiki, 26, 256-267.

Clifton, C., Jr., Staub, A., \& Rayner, K. (2007). Eye movements in reading words and sentences. In R. P. G. van Gompel, M. H. Fischer, W. S. Murray, \& R. L. Hill (Eds.), Eye movements: A window on mind and brain (pp. 341-369). Amsterdam, The Netherlands: Elsevier.
Cop, U., Dirix, N., Drieghe, D., \& Duyck, W. (2017). Presenting GECO: An eyetracking corpus of monolingual and bilingual sentence reading. Behavior Research Methods, 49, 602-615.

Crawford, T. J., Devereaux, A., Higham, S., \& Kelly, C. (2015). The disengagement of visual attention in Alzheimer's disease: A longitudinal eye-tracking study. Frontiers in Aging Neuroscience, 7, 118.

Crepaldi, D., Berlingeri, M., Paulesu, E., \& Luzzatti, C. (2011). A place for nouns and a place for verbs? A critical review of neurocognitive data on grammatical-class effects. Brain and Language, 116, 33-49. doi:https://doi.org/10.1016/j.bandl.2010.09.005

Dambacher, M., Dimigen, O., Braun, M., Wille, K., Jacobs, A. M., \& Kliegl, R. (2012). Stimulus onset asynchrony and the time course of word recognition: Effects of frequency and predictability on eventrelated potentials. Neuropsychologia, 50, 1852-1870.

Dambacher, M., Rolfs, M., Göllner, K., Kliegl, R., \& Jacobs, A. (2009). Event-related potentials reveal rapid verification of predicted visual input. PLoS ONE, 4, e5047:1-8. doi:https://doi.org/10.1371/journal. pone. 0005047

Demberg, V., \& Keller, F. (2008). Data from eye-tracking corpora as evidence for theories of syntactic processing complexity. Cognition, 109, 193-210.

Efremova, T. F. (2000). Novyj tolkovo-slovoobrazovatel'nyj slovar' russkogo jazyka [The new Russian language dictionary]. Moscow, Russia: Russkij jazyk.

Engbert, R., \& Kliegl, R. (2001). Mathematical models of eye movements in reading: A possible role for autonomous saccades. Biological Cybernetics, 85, 77-87.

Engbert, R., Longtin, A., \& Kliegl, R. (2002). A dynamical model of saccade generation in reading based on spatially distributed lexical processing. Vision Research, 42, 621-636. doi:https://doi.org/10. 1016/S0042-6989(01)00301-7

Engbert, R., Nuthmann, A., Richter, E. M., \& Kliegl, R. (2005). SWIFT: A dynamical model of saccade generation during reading. Psychological Review, 112, 777-813. doi:https://doi.org/10.1037/ 0033-295X.112.4.777

Fernández, G., Shalom, D. E., Kliegl, R., \& Sigman, M. (2014). Eye movements during reading proverbs and regular sentences: The incoming word predictability effect. Language, Cognition and Neuroscience, 29, 260-273.

Genzel, D., \& Charniak, E. (2002). Entropy rate constancy in text. In Proceedings of the 40th Annual Meeting on Association for Computational Linguistics (pp. 199-206). Stroudsburg, PA: Association for Computational Linguistics.

Gibson, E. (2000). The dependency locality theory: A distance-based theory of linguistic complexity. In A. Marantz, Y. Miyashita, \& W. O'Neil (Eds.), Image, language, brain: Papers from the first mind 
articulation project symposium (pp. 94-126). Cambridge, MA: MIT Press.

Hale, J. (2001). A probabilistic early parser as a psycholinguistic model. In Proceedings of the second meeting of the North American Chapter of the Association for Computational Linguistics on Language Technologies (pp. 1-8). Stroudsburg, PA: Association for Computational Linguistics.

Heister, J., Würzner, K. M., \& Kliegl, R. (2012). Analysing large datasets of eye movements during reading. In J. S. Adelman (Ed.), Visual word recognition. Vol. 2: Meaning and context, individuals and development (pp. 102-130). Hove, UK: Psychology Press.

Hohenstein, S., \& Kliegl, R. (2017). remef: Remove partial effects (R package version 1.0.6.9000). https://github.com/hohenstein/remef/

Huey, E. B. (1908). Basic studies on reading. New York, NY: Basic Books.

Husain, S., Vasishth, S., \& Srinivasan, N. (2015). Integration and prediction difficulty in Hindi sentence comprehension: Evidence from an eye-tracking corpus. Journal of Eye Movement Research, 8(2), 112. doi:https://doi.org/10.16910/jemr.8.2.3

Hyönä, J., Laine, M., \& Niemi, J. (1995). Effects of a word's morphological complexity on readers' eye fixation patterns. In J. M. Findlay, R. Walker, \& R. W. Kentridge (Eds.), Eye movement research: Mechanisms, processes and applications (pp. 445-452). Amsterdam, The Netherlands: Elsevier.

Hyönä, J., Yan, M., \& Vainio, S. (2017). Morphological structure influences the initial landing position in words during reading Finnish. The Quarterly Journal of Experimental Psychology, 1-10.

Jonkers, R., \& Bastiaanse, R. (1996). The influence of instrumentality and transitivity on action naming in Broca's and anomic aphasia. Brain and Language, 55, 37-39.

Jouravlev, O., \& Jared, D. (2018). Cross-script orthographic and phonological preview benefits. Quarterly Journal of Experimental Psychology, 71, 11-19. doi:https://doi.org/10.1080/17470218. 2016.1226906

Keller, F. (2004). The entropy rate principle as a predictor of processing effort: An evaluation against eye-tracking data. In Proceedings of the Conference on Empirical Methods in Natural Language Processing, Barcelona 2004 (pp. 317-324). New York, NY: ACM Press.

Kennedy, A., \& Pynthe, J. (2005). Parafoveal-on-foveal effects in normal reading. Vision Research, 45, 153-168.

Kim, Y. S., Radach, R., \& Vorstius, C. (2012). Eye movements and parafoveal processing during reading in Korean. Reading \& Writing, 25, 1053-1078.

Kliegl, R., Grabner, E., Rolfs, M., \& Engbert, R. (2004). Length, frequency, and predictability effects of words on eye movements in reading. European Journal of Cognitive Psychology, 16, 262-284. doi: https://doi.org/10.1080/09541440340000213

Kliegl, R., Nuthmann, A., \& Engbert, R. (2006). Tracking the mind during reading: The influence of past, present, and future words on fixation durations. Journal of Experimental Psychology: General, 135, 12-35. doi:https://doi.org/10.1037/0096-3445.135.1.12

Kuperman, V., Bertram, R., \& Baayen, R. H. (2010). Processing tradeoffs in the reading of Dutch derived words. Journal of Memory and Language, 62, 83-97.

Kuperman, V., Dambacher, M., Nuthmann, A., \& Kliegl, R. (2010). The effect of word position on eye-movements in sentence and paragraph reading. Quarterly Journal of Experimental Psychology, 63, 1838-1857.

Kuperman, V., \& Van Dyke, J. A. (2011). Effects of individual differences in verbal skills on eye-movement patterns during sentence reading. Journal of Memory and Language, 65, 42-73.

Laubrock, J., \& Kliegl, R. (2015). The eye-voice span during reading aloud. Frontiers in Psychology, 6, 1432. doi:https://doi.org/10.3389/ fpsyg.2015.01432

Lewis, G. E. (1972). Multilingualism in the Soviet Union: Aspects of language policy and its implementation. The Hague, The Netherlands: Mouton De Gruyter.
Li, X., Bicknell, K., Liu, P., Wei, W., \& Rayner, K. (2014). Reading is fundamentally similar across disparate writing systems: A systematic characterization of how words and characters influence eye movements in Chinese reading. Journal of Experimental Psychology: General, 143, 895-913.

Liversedge, S. P., Drieghe, D., Li, X., Yan, G., Bai, X., Hyönä, J. (2016). Universality in eye movements and reading: A trilingual investigation. Cognition, 147, 1-20.

Lüdecke, D. (2017). sjPlot: Data visualization for statistics in social science ( $\mathrm{R}$ package version 2.3.3). Retrieved from https://CRAN.Rproject.org $/$ package $=$ sjPlot

Lyashevskaya, O. N., \& Sharov, S. A. (2009). Chastotnyj Slovar' Sovremennogo Russkogo Jazyka (na Materialakh Natsional'nogo Korpusa Russkogo Jazyka) [Frequency Dictionary of Modern Russian (based on the materials of the Russian National Corpus)]. Moscow, Russia: Azbukovnik.

Mätzig, S., Druks, J., Masterson, J., \& Vigliocco, G. (2009). Noun and verb differences in picture naming: Past studies and new evidence. Cortex, 45, 738-758. doi:https://doi.org/10.1016/j.cortex.2008.10.003

Paterson, K. B., Almabruk, A. A., McGowan, V. A., White, S. J., \& Jordan, T. R. (2015). Effects of word length on eye movement control: The evidence from Arabic. Psychonomic Bulletin \& Review, 22, 1443-1450.

Paterson, K. B., McGowan, V. A., White, S. J., Malik, S., Abedipour, L., \& Jordan, T. R. (2014). Reading direction and the central perceptual span in Urdu and English. PLoS ONE, 9, e88358. doi:https://doi.org/ 10.1371/journal.pone.0088358

Pollatsek, A., Bolozky, S., Well, A. D., \& Rayner, K. (1981). Asymmetries in the perceptual span for Israeli readers. Brain and Language, 14, 174-180.

R Core Team. (2016). R: A language and environment for statistical computing. Vienna, Austria: R Foundation for Statistical Computing. Retrieved from https://www. R-project.org/

Rayner, K. (1998). Eye movements in reading and information processing: 20 years of research. Psychological Bulletin, 124, 372-422. doi: https://doi.org/10.1037/0033-2909.124.3.372

Rayner, K. (2009). Eye movements and attention in reading, scene perception, and visual search. Quarterly Journal of Experimental Psychology, 62, 1457-1506. doi:https://doi.org/10.1080/ 17470210902816461

Rayner, K., Chace, K. H., Slattery, T. J., \& Ashby, A. (2006). Eye movements as reflections of comprehension processes in reading. Scientific Studies of Reading, 10, 241-255. doi:https://doi.org/10. 1207/s1532799xssr1003 3

Rayner, K., Pollatsek, A., Drieghe, D., Slattery, T. J., \& Reichle, E. D. (2007). Tracking the mind during reading via eye movements: Comments on Kliegl, Nuthmann, and Engbert (2006). Journal of Experimental Psychology: General, 136, 520-529. doi:https://doi. org/10.1037/0096-3445.136.3.520

Reichle, E. D., Pollatsek, A., Fisher, D. L., \& Rayner, K. (1998). Toward a model of eye movement control in reading. Psychological Review, 105, 125-157. doi:https://doi.org/10.1037/0033-295X.105.1.125

Risse, S., Hohenstein, S., Kliegl, R., \& Engbert, R. (2014). A theoretical analysis of the perceptual span based on SWIFT simulations of the $n+2$ boundary paradigm. Visual Cognition, 22, 283-308.

Sainio, M., Hyönä, J., Bingushi, K., \& Bertram, R. (2007). The role of interword spacing in reading Japanese: An eye movement study. Vision Research, 47, 2575-2584.

Schad, D. J., \& Engbert, R. (2012). The zoom lens of attention: Simulating shuffled versus normal text reading using the SWIFT model. Visual Cognition, 20, 391-421.

Schad, D. J., Nuthmann, A., \& Engbert, R. (2012). Your mind wanders weakly, your mind wanders deeply: Objective measures reveal mindless reading at different levels. Cognition, 125, 179-194.

Schilling, H. E. H., Rayner, K., \& Chumbley, J. I. (1998). Comparing naming, lexical decision, and eye fixation times: Word frequency 
effects and individual differences. Memory \& Cognition, 26, 12701281. doi:https://doi.org/10.3758/BF03201199

Share, D. (2008). On the Anglocentricities of current reading research and practice: The perils of overreliance on an "outlier" orthography. Psychological Bulletin, 134, 584-615.

Szekely, A., D’Amico, S., Devescovi, A., Federmeier, K., Herron, D., Iyer, G., ... Bates, E. (2005). Timed action and object naming. Cortex, 41, 7-25. doi:https://doi.org/10.1016/S0010-9452(08)70174-6

Tiffin-Richards, S. P., \& Schroeder, S. (2015). Word length and frequency effects on children's eye movements during silent reading. Vision Research, 113, 33-43.

Tikhonov, A. N. (2003). Slovoobrasovatel'nyj slovar' russkogo yazyka v dvux tomax [Word formation dictionary of Russian in two volumes]. Moscow, Russia: Astrel.

Tinker, M. A. (1958). Recent studies of eye movements in reading. Psychological Bulletin, 55, 215-231. doi:https://doi.org/10.1037/ h0041228

Tsai, J. L., Kliegl, R., \& Yan, M. (2012). Parafoveal semantic information extraction in traditional Chinese reading. Acta Psychologica, 141, 17-23.
Wickham, H. (2016). ggplot2: Elegant graphics for data analysis. New York, NY: Springer.

Winskel, H., Radach, R., \& Luksaneeyanawin, S. (2009). Eye movements when reading spaced and unspaced Thai and English: A comparison of Thai-English bilinguals and English monolinguals. Journal of Memory and Language, 61, 339-351.

Yan, G., Tian, H., Bai, X., \& Rayner, K. (2006). The effect of word and character frequency on the eye movements of Chinese readers. British Journal of Psychology, 97, 259-268.

Yan, M., Kliegl, R., Richer, E. M., Nuthmann, A., \& Shu, H. (2010). Flexible saccade-target selection in Chinese reading. Quarterly Journal of Experimental Psychology, 63, 705-725.

Yan, M., Richter, E. M., Shu, H., \& Kliegl, R. (2009). Readers of Chinese extract semantic information from parafoveal words. Psychonomic Bulletin \& Review, 16, 561-566. doi:https://doi.org/10.3758/PBR. 16.3.561

Yan, M., Zhu, W., Shu, H., Yusupu, R., Miao, D., Krügel, A., \& Kliegl, R. (2014). Eye movements guided by morphological structure: Evidence from the Uighur language. Cognition, 132, 181-215. 